\title{
Some Aspects of Analysis of Gaits in Educational Vision
}

\author{
Raiola Gaetano ${ }^{1}$ \\ Tafuri Domenico ${ }^{1}$ \\ Lipoma Mario² \\ 1 University Parthenope of Naples, Italy \\ 2University Kore of Enna, Italy
}

\section{Doi:10.5901/mjss.2016.v7n2s1p416}

\begin{abstract}
This article defined, investigated, analyzed and elaborated an understanding of the movement observed. The acquisition and analysis of human movement offers employment opportunities in various sectors, such as animation, sports applications, educational and clinical rehabilitation. The analysis of human movement aims measurement and description of the biomechanical elements that characterize the performance of an act, in order to improve the whole process of teaching, learning and rehabilitative. Are mentioned some of the work on the perception of walking and computational methods to measure gait. And finally, it is suggested a methodology to investigate issues related to human movement, in which the bodily manifestations and attitudes play a role in diffusing information that can be useful for a recording of behaviors and ways of being authentic.
\end{abstract}

Keywords: human movement, biomechanical analysis, markers, motor act.

\section{Introduction}

The human gait is a movement pattern of the base, is a particular feature of a person and is determined by several components, such as weight, muscle mass, limb length, footwear and posture. The gait can be used as biometric measurement to recognize and classify people. Wanting to extend the definition of gait to include other aspects of the person, such as: the proportions of the bust, the clothing, the amplitude of oscillation of the arm, the phases of a cycle of walking, etc ... The acquisition and analysis of the Human movement today are employed in different sectors: animation, sports applications and clinical rehabilitation. In particular, for applications biomechanical and clinical methods currently most common provide for a controlled laboratory environment and the use of marker applied to the skin of the patient.

In recent years, attention has turned towards non-invasive systems based on the acquisition of synchronized video sequences obtained with common cameras. The modern systems for the analysis of movement are often made from more instruments interfaced, each with the purpose of investigating a different aspect of the movement itself: for example using laboratories with special camera systems, for the reconstruction of three-dimensional scene, force platforms and pressure, for the study of the forces that the human body exchanges with the ground, and electromyography, for the recording of the electrical activity associated with muscle contraction. The potential applications of this analysis find their ways are in different sectors: in the context of video surveillance, entertainment (video games, virtual environments, digital animation) in clinical and rehabilitative, educational and sport skills (Raiola, 2015abc, Raiola Tafuri 2015ab, Raiola, 2014abc, Raiola, 2012, Raiola, Di Tore, 2012abc, Raiola et al. 2015abc, Raiola et al., 2013ab).

These last two interest us most. An educational research is interested in issues related to education, to all processes, attitudes and behavior active to facilitate the acquisition of knowledge (Gaetano, Rago, 2014, Gaetano et al., 2015ab). An education system cannot be satisfied and should not deplete its action only in the implementation of a system for taking charge of the welfare of the weaker type, as in the modification and change in the contexts and processes of teaching / learning, in order to generate same development opportunities for those who live particular situations of educational difficulties and learnings, physical (Raiola et al, 2016ab, Altavilla, Raiola, 2014, Altavilla et al., 2014ab, 2015ab). A search, however, in the field of motor-sports interested to investigate aspects related to human movement, wherein the body, the attitudes and the movement play a role diffuser of information and therefore valuable for a recording of authentic behaviors and ways of being (Di Tore, Raiola, 2012ab, Gomez Paloma, lanes, 2014). In this way, it is important to deep the digital instruments and the related usability to sports (Parisi, Raiola, 2014ab, Napolitano et al, 2013abc, Polidoro et al., 2013, Tursi et al., 2013ab). 


\section{Aim}

Suggest a technique for acquisition and analysis of human movement that aims to measure and description of the biomechanical elements that characterize the performance of an act, in order to improve the whole process of teaching and learning.

\section{Method}

The protocol IOR-gait (Leardini et al. 2007) was developed in 2007 at the Rizzoli Orthopaedic Institute, Bologna. The Laboratory, present in the Institute, is a reference center for the functional evaluation of patients with diseases of musculoskeletal system for evaluation, diagnosis and treatment; has instrumentation systems measure positions, using stereo-systems, force platforms, systems baropodometric and electromyography. With these tools, you can monitor with great detail the kinematics and dynamics of the segments and joints involved in locomotion. This protocol was established as a compromise between the reduction of the time of preparation of the patient, through the use of a few markers, and the accuracy and reliability of the results, thanks to the calibration of anatomical points.

This methodology is chosen for its complexity and efficacy in diagnostic process of athletes, amateurs and students. For this reason, its dissemination in rehabilitation, public health and sports is very present.

The marker-set and the anatomical points to consider are shown in Figure 1. The anatomical reference systems are defined according to the guidelines of the Protocol (Cappozzo, et al., 1995) and are calibrated only six anatomical points: the femoral epicondyle medial left and right, the apex of the outer left and right medial malleolus, the second metatarsal head left and right.

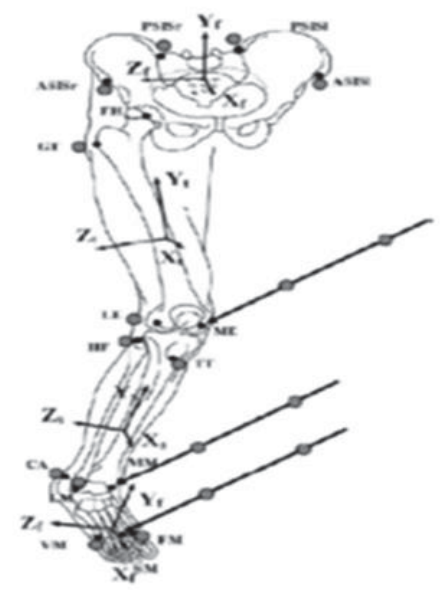

Figure 1. Schematic representation of the position of the anatomical landmarks used with protocol IOR-gait.

\section{Results}

The acquisition of the movement through a market-based approach requires to apply on the body of the subject under consideration appropriate markers; these were applied following the directives of the Protocol IOR-gait, more precisely 14 seats directly on the seventh cervical vertebra, on the fifth lumbar vertebra, on the left and right acromion and the landmarks of the right lower limb (epicondyles medial and lateral head fibula, tibial tuberosity, lateral and medial malleolus, calcaneus and first, second and fifth metatarsal) and 12 divided into four clusters in a diamond shape on the right thigh, lower leg and right pelvis right and left (Figure 2). 

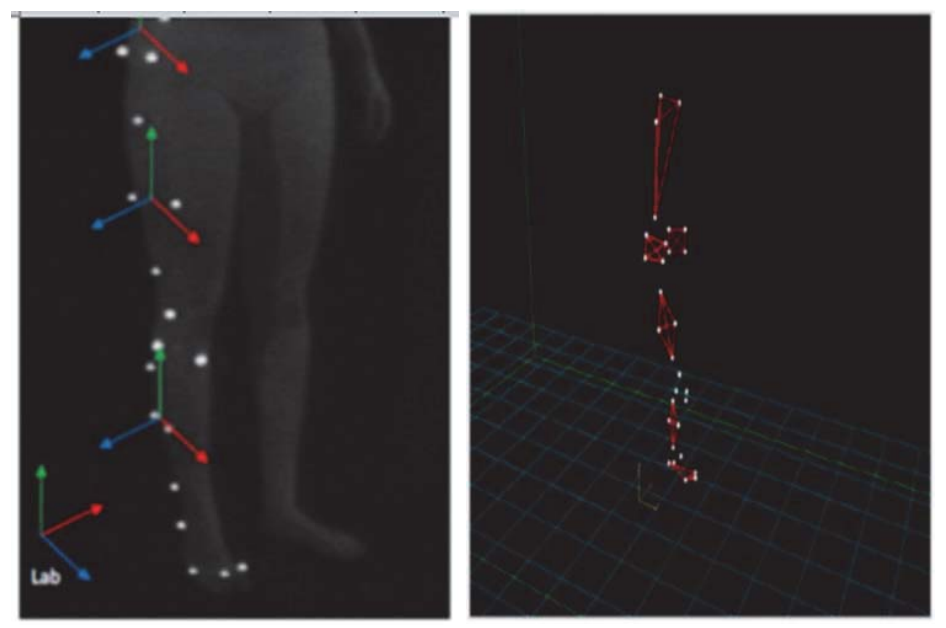

Figure 2. Representation of the arrangement of the markers Figure 3. Representation of the reference systems engineers pelvis

Before you can proceed with the acquisition of real movement is necessary to perform a calibration anatomical reference anatomical landmarks during a static phase. The technique marker-based defining the technical systems of each segment from three non-aligned marker placed on the latter using the method of Chao-Morrey (1978). The result is shown in Figure 3, the system of the basin calculated with the technique of marker-based.

\section{Discussion}

Dates on the gait can be used to assess the disease in various ways. For example, parameters of step, such as walking speed, step length and cadence provide an overview on the quality of gait (Vaughan CL., et al., 2003) . Johansson had already demonstrated in 1970 that observers could recognize the gait through elements to their families just looking video sequences of lights placed on the joints of the person under observation. So, in theory, the joint angles are sufficient to recognize people by their gait. However, using only joint angles are ignored traits associated with the appearance of people, such as long hair or bald, personal clothing and accessories. Below are mentioned some of the work to measure gait. Several researchers have concluded that the gait is indicative of gender and identity of a person. Johansson (1975) has used lights positioned on the joints of the person and showed observers motion sequences of lights as a person walks. Observers were able to identify gender and, in cases where the observer had familiar with the subject, the identity of the person that walks. Cutting (1978) have analyzed the human gait using light panels moveable (MLD), similar to those used by Johansson and have showed that observers could identify people in the approximate precision of $70 \%$ using only visual signals by MLD. In the last thirty years, the systems that have found increased use are precisely the optoelectronic systems, through which you acquire positions snapshots taken into space by special reflective markers, placed on specific anatomical points. From the trajectories of the markers obtained can be traced back to the relative movement between two adjacent body segments, with the aim of precisely defining the movement of the joint. A protocol for the analysis of the movement defines the procedure to be followed to acquire and process the movement of a person, in a mode standardized and repeatable. Since that the position of the marker on the body surface influence the precision and accuracy with which it is described the movement of the person, is essential to ensure the maximum visibility of the markers on the part of the cameras, there is not an overcrowding of the markers that hinder the identification of the trajectory of a single marker, at least three markers are used to identify a body segment. The protocol described has been prepared in based on the type of movement to be analyzed and to pathology of the subjects to be studied and has been validated and recognized by the international scientific community.

\section{Conclusions}

In this article has been analyzed an acquisition technique and analysis of human movement, which by using a few 
markers on the skin; however, this technique, even today, presents some limitations from the point of view of accuracy. It is desirable that the application of the methodology presented in this article , together with the use of a greater number of cameras, could lead to an increase of the accuracy in the detection and analysis of the movement. In the areas sports and the clinical application of motion capture techniques and mechanisms that are behind, requires great precision of the method . It is clear that the technique marker - based, where you must prepare the laboratory, calibrate the system and place the marker on the person, involves a considerable time, is expensive, and can introduce experimental artifacts . Finally, the overall dimensions of the equipment itself can be it difficult to use in special conditions, for example in the sports field, or in other cases reduce the naturalness of the movement by the subject under examination. During the motor act, furthermore, the markers are subject to movements, produced by the movement of the skeletal and from the markers itself; this can have negative effects on the accuracy and precision of the measurement. For these reasons , emerging techniques and research in the field of computer vision are leading to the rapid development of marker less .

\section{References}

Altavilla, G., Raiola, G., 2014, Global vision to understand the game situations in modern basketball Journal of Physical Education and Sport Vol 14 issue 4

Altavilla G., Tafuri D., Raiola, G., 2014a, Some aspects on teaching and learning by physical activity Sport Science vol 71

Altavilla, G., Tafuri, D., Raiola, G., 2014b, Influence of sports on the control of static balance in physical education at school Journal of Physical Education and Sport Vol 143 pp. 351 - 354

Altavilla G, Furino F, Di Palmo M, Raiola G, 2015a, Physical skills, sport learning and socio-affective education Sport Science, 81 supplement

Altavilla G, Furino F, Di Palmo M, Raiola G, 2015b, The child hypokinetic and the overtrained Sport Science, 81 supplement

Cappozzo A., Catani, F., Della Noce, U, Leardini, A, 1995, Position and orientation in space of bones during movement: anatomical frame definition and determination., Clinical Biomechanics, Vol. 10, p. 171-178.

Chao E. Y., Morrey B. F., Three dimensional rotation of the elbow. 1978, Journal of biomechanics, Vol. 11, p. 57-73.

Cutting J.1978, A biomechanical invariant for gait perception. Journal of Experimental Psychology: Human Perception and Performance, 43

Di Tore, P.A., Raiola, G. 2012a, Exergame-design and motor activities teaching: An overview of scientific paradigms on motor control Mediterranean Journal of Social Sciences vol 311

Di Tore, P.A, Raiola, G., 2012b, Case study on Physical Education and Sport in Naples, Mediterranean Journal of Social Sciences, vol 3 11

Gaetano R., Rago, V., 2014, Preliminary study on effects of hiit-high intensity intermittent training in youth soccer players Journal of Physical Education and Sport vol 142

Gaetano R., Domenico T., Gaetano A., 2015a Physical activity and its relation to body and ludic expression in childhood Mediterranean Journal of Social Sciences Vol. 6, № 3

Gaetano R., Gomez F.P., Gaetano A., 2015b, Anxiety In The Youth Physical And Sport Activity, Mediterranean Journal of Social Sciences Vol. 6, № 3

Gomez Paloma F., lanes D., 2014, Sport and physical education to practice inclusive, Centro Studi Erickson, Trento

Johansson G., 1975, Visual motion perception. Scientific American, USA

Leardini A., 2007, A new anatomically based protocol for gait analysis in children., Gait and posture, Vol. 26

Parisi F, Raiola G., 2014a, Video analysis in youth volleyball team, Journal of Human Sport and Exercise vol 91

Parisi F, Raiola G., 2014b, The serve in under 12-13 Italian volleyball team, Journal of Human Sport and Exercise vol 91

Napolitano, S., Di Tore, P.A.,Raiola, G., 2013a, High diving: Evaluation of water impact and considerations on training methods Journal of Human Sport and Exercise vol 82

Napolitano S, Tursi D, Di Tore P A, Raiola G, 2013b, Tactics -based on waterpolo training. Journal of Human Sport and Exercise vol 82

Napolitano S, Tursi D, Raiola G, 2013c, Waterpolo women's pattern tactical experience of an Italian team Journal of Human Sport and Exercise vol 83

Polidoro. L, Bianchi F, Di Tore P A, Raiola G, 2013, Futsal training by video analysis Journal of Human Sport and Exercise vol 82

Raiola G., Altavilla G., Tafuri D, Lipoma M, 2016a, Analysis of learning of shot in basketball, Journal of physical education, vol. 51

Raiola G, Altavilla G, Di Tore P A, 2016b, Analysis on some aspects of the service in volleyball, Sport Science, 91

Raiola G., 2015a, Basketball feint and non-verbal communication: empirical framework Journal of Human Sport and Exercise vol 101 supplement

Raiola G., 2015b, Sport skills and mental health, Journal of Human Sport and Exercise vol 101 supplement

Raiola G., 2015c, Inclusion in sport dance and self perception, Sport Science, 81

Raiola G., Tafuri D., 2015a, Assestment and periodization in amateur soccer team, Sport science, vol 8 supplement 2

Raiola, G., 2014a, Motor control and learning skills according to cognitive and ecological dynamic approach in a vision on behaviorism, cognitive, Gestalt and phenomenology theories Mediterranean Journal of Social Sciences vol 515

Raiola, G., 2014b, Teaching method in young female team of volleyball Journal of Physical Education and Sport vol 141

Raiola, G., 2012, Bodily communication in volleyball between human and experimental sciences Mediterranean Journal of Social 
Sciences vol 3

Raiola G, Tafuri D., 2015b, Teaching method of physical education and sports by prescriptive or heuristic learning. Journal of Human Sport and Exercise vol 101 supplement

Raiola G., Di Tore A., 2012a, Non-verbal communication and volleyball: A new way to approach the phenomenon Mediterranean Journal of Social Sciences vol 3

Raiola, G.,Di Tore, P.A 2012b, Statistical study on bodily communication skills in volleyball to improve teaching methods Journal of Human Sport and Exercise vol. 72

Raiola, G., Di Tore P.A., 2012c, Bodily communication skills and its incidence on female volleyball championship to enhance didactics Journal of Human Sport and Exercise vol 71

Raiola G., Lipoma, M., Tafuri D., 2015a, Postural control in young soccer players: differences between the cognitive approach and ecological-dynamic one, Journal of Human Sport and Exercise vol 101 supplement

Raiola G, Tafuri D., Paloma G. F., Lipoma M., 2015b, Bodily Communication in basketball Sport Science, 82

Raiola G, Tafuri D., Paloma G. F., Lipoma M., 2015c, Case study on mental health and physical activity Sport Science, 82

Raiola, G.,Scassillo, I.,Parisi, F.,Di Tore, P.A., 2013a Motor imagery as a tool to enhance the didactics in physical education and artistic gymnastic Journal of Human Sport and Exercise vol 82

Raiola, G.,Giugno, Y.,Scassillo, I., Di Tore, P.A., 2013b, An experimental study on Aerobic Gymnastic: Performance analysis as an effective evaluation for technique and teaching of motor gestures Journal of Human Sport and Exercise vol 82

Vaughan CL, Langerak NG, O'Malley MJ., 2003, Neuromaturation of human locomotion revealed by non-dimensional scaling. Experimental Brain Research

Tursi, D.,Napolitano, S.,Di Tore, P.A.,Raiola, G. 2013a, Arm stroke: A comparative analysis between competitive swimming and water polo athletes Journal of Human Sport and Exercise vol 82

Tursi, D.,Napolitano, S.,Polidoro F, Raiola, G. 2013b, Video analysis as an instrument in juvenilia soccer training Journal of Human Sport and Exercise vol 83. 